\title{
Legalising physician-assisted suicide in South Africa: Should it even be considered?
}

\author{
R K Jacobs, MB ChB \\ Centre for Medical Ethics and Law, Faculty of Medicine and Health Sciences, Stellenbosch University, Cape Town, South Africa
}

Corresponding author: RK Jacobs (ryankjacobs16@gmail.com)

For many years, euthanasia and physician-assisted suicide (PAS) have been topics that no one dared to mention. However, over the past few decades, the subject has emerged as a very pertinent issue around the world, for a number of reasons - so much so that these life-ending practices have already been legalised or decriminalised in some developed countries, such as Belgium, the Netherlands and Switzerland, and within certain states of the USA. In the states and countries where the practices have been legalised, or at least decriminalised, the effects of the legalisation have been relatively well documented. On the other hand, in countries like South Africa (SA), where they are illegal, whether or not they should be legalised (taking into consideration all the associated benefits and consequences) should be discussed, and a consensus reached, sooner rather than later. A consensus regarding the feasibility of legalising euthanasia and/or PAS in SA is needed because these practices (or mere requests for them) are becoming increasingly common, especially among people with terminal illnesses. Furthermore, the relative ease with which patients who desperately seek to end their life through either of the aforementioned methods, and are able to access them - by applying for them in countries where the pertinent laws and regulations are adjudged to be more liberal - is alarming. This highlights the importance and need for each country to set clear laws or parameters (and regulations, where applicable) that relate to these life-ending practices.

S Afr J Bioethics Law 2018;11(2):66-69. DOI:10.7196/SAJBL.2018.v11i2.635

The medical practice of euthanasia and physician-assisted suicide (PAS) has remained a controversial and taboo topic, not only in South Africa (SA), but throughout the world for a number of years. Worldwide, euthanasia and PAS are defined as two distinct means by which an end to a patient's life can be brought about, through various actions. Materstvedt et al. ${ }^{[1]}$ define euthanasia as 'a doctor intentionally killing a person by the administration of drugs, at that person's voluntary and competent request', while PAS is defined as 'a doctor intentionally helping a person commit suicide by providing drugs for self-administration, at that person's voluntary and competent request'.[1] SA law does not discriminate between the two, but instead regards both as a form of active euthanasia. ${ }^{[2]}$ Moreover, SA law also clearly states that 'a person who assists another to commit suicide will be guilty of murder or culpable homicide.[?] This clearly defined law is therefore responsible for (some) physicians' reluctance to perform these procedures - for fear of prosecution. However, with an everageing community and an increasing incidence of terminal disease, the prospects of more patients opting for life-ending interventions can possibly be expected. ${ }^{[3]}$ Noticeable increases in respect for patient autonomy in recent times have further strengthened the call for the legalisation of PAS, especially in countries where it is currently illegal, like $S A{ }^{[4]}$ This report is therefore aimed at determining the practicality and consequences of legalising PAS in SA.

\section{International and SA perspectives}

The debate regarding the legalisation of euthanasia and PAS has been ongoing for a number of decades, both in SA and internationally. As a result, a number of countries (Belgium, the Netherlands and a few states within the USA) have since moved to legalise or at least decriminalise euthanasia and/or PAS. ${ }^{[5]}$ Prior to the legalisation of PAS, concerns regarding the victimisation of vulnerable groups, namely the elderly, women, people with low educational status, the poor and those with physical disabilities, were raised. ${ }^{[6]}$ A recently published review article sought to establish whether a definite risk of victimisation was truly experienced by the aforementioned groups subsequent to the legalisation of PAS. The authors reported that 'no heightened risk' of victimisation for these groups of patients existed..$^{[6]}$ Table 1 is adapted from the abovementioned article, and seeks to clarify why the authors regarded certain groups as experiencing 'no heightened risk'. However, as illustrated, although there is no risk associated with the majority of the vulnerable risk groups (as described), the same report found that there was one particular group of patients who were at 'heightened risk'! ${ }^{[6]}$ This group was identified as those living with HIV/ AIDS. It has been reported that $22 \%$ of a cohort of 131 homosexual men suffering from HIV/AIDS had died through the assistance of a physician - either by PAS or euthanasia. ${ }^{[6]}$ The authors suggest that the reason for the risk in this group of patients is attributable to the period during which these assisted suicides were performed between 1985 and 1992. They believe that a major reason for these patients opting for either PAS or euthanasia was directly related to the inability at the time to effectively treat AIDS. ${ }^{[6]}$

It was also previously believed that legalising PAS would result in a decrease in the rates of non-assisted suicide..$^{[7]}$ A study conducted by Jones et al. ${ }^{[8]}$ that looked at the effects of legalising PAS and its influence on the overall rates of suicide in the USA found that the 'introduction of PAS was neither associated with a reduction in 
Table 1. Summary of report findings on heightened risk for presumed vulnerable groups, and PAS ${ }^{[6]}$

\begin{tabular}{ll}
\hline Group & Finding \\
\hline Elderly people & $\begin{array}{l}\text { Data from Oregon showed that only } 10 \% \text { of deaths of patients }>85 \text { years were due to PAS, while the } \\
\text { overall percentage of deaths of people aged } 85 \text { and older was recorded at } 21 \% . \text { Meanwhile, in the } \\
\text { Netherlands, only } 2.8 \% \text { of deaths in patients }>65 \text { years recorded in } 2005 \text { were as a result of PAS. }\end{array}$ \\
It was reported that both men and women were equally likely to opt for and receive assistance in \\
dying. In Oregon, it was reported that only $46 \%$ of individuals who received assisted dying were \\
women. \\
Data from Oregon suggest that the likelihood of dying by means of PAS was linked to higher \\
educational levels. 'Terminally ill college graduates in Oregon were 7.6 times more likely to die with \\
physician assistance than those without a high school diploma'. \\
Although not clearly documented as poor or not at the time of request for and execution of PAS, \\
data from both Oregon and the Netherlands suggested that those who opted for PAS were relatively \\
affluent, with life insurance, higher levels of education and addresses that suggested affluence.
\end{tabular}

PAS = physician-assisted suicide

non-assisted suicide rates nor with an increase in the mean age of non-assisted suicide. ${ }^{[8]}$ In the states of Oregon and Washington, nonassisted and assisted-suicide rates were compared from before and after the legalisation of PAS (data were recorded from 1998 to 2013 for Oregon and 2009 to 2013 for Washington state) ${ }^{[8]}$ Prior to the legalisation of PAS in Oregon and Washington, total suicide rates (per 100000 ) were documented as 15.9 and 13.3 , respectively, while after its legalisation they were recorded at 16.9 and 15.3 for Oregon and Washington, respectively - with assisted-suicide rates accounting for 1.2 per 100000 suicides in both states ${ }^{[8]}$ Although these data might, at first glance, suggest that legalising PAS has resulted in an overall increase in suicide rates, it is important to note that the increase is not solely influenced by PAS, as it had accounted for only 1.2 suicides per 100000 since its legalisation, and the general suicide rate had also increased.

As mentioned, the debate around the legalisation of PAS in SA has been ongoing for a number of years - with a substantial conclusion yet to be reached. Although PAS is technically illegal in SA, in many cases in recent years, courts have shown various degrees of leniency in rulings relating to PAS (and euthanasia). The most recent case, presented in the Gauteng High Court in 2015, illustrates this point. Mr Stransham-Ford suffered from terminal cancer, and after numerous failed attempts at various medical treatment options, approached the court with an application to have his death hastened. Mr StranshamFord's application, additionally, included the exoneration of the implicated doctor. ${ }^{[9]}$ The application for active euthanasia was heard by the judge, who ruled in favour of Mr Stransham-Ford receiving physician assistance in dying. Mr Stransham-Ford, unfortunately, died before the ruling was passed. In this case, the ruling was declared as being in line with the SA Constitution, which states that every person has the right to die with dignity. ${ }^{[9]}$ Although the Constitution ${ }^{[10]}$ holds that every person has the right to have their dignity respected and protected (as stated in section 10), and furthermore, that everyone has the right to have control over their (own) body (section 12), these stipulations are not specific to, and cannot explicitly be extended to, life-ending circumstances. Although the High Court ruled in favour of the applicant, the decision was later challenged in the Supreme Court of Appeal (SCA), and was subsequently overturned. The SCA judge, however, acknowledged that decisions regarding euthanasia/ PAS cannot be taken by a lower court alone, and that it is 'a doctrine which may be in the womb of time, but whose birth is distant', while further acknowledging that 'it follows that it cannot be said that in the current state of our law that PAS is in all circumstances unlawful' - thus leaving room for exploration. ${ }^{[1]}$

Prior to the adoption of the current SA Constitution, cases such as Clark v Hurst $\mathrm{NO}^{[12]}$ were judged in accordance with the 'legal convictions of the community. However, since being adopted as the supreme rule by which the country is governed, the Constitution has since held the notion that courts should no longer be influenced by public opinion, but rather through the values upheld by the Constitution itself. ${ }^{[13]}$ This therefore implies that the SA public has little to no direct influence on the outcomes of individual cases, as presented in a court of law. However, since the Constitution holds individualism on the same level as communitarianism, in order for new laws or policies to be informed, the views of all key role-players must be evaluated. ${ }^{[14]}$ Key role-players to be involved in informing policy/laws relating to PAS would ultimately include the general public, among many other individuals, such as doctors.

\section{Arguments for and against PAS}

At present, the strongest argument for the legalisation of both euthanasia and PAS is the principle of respect for patient autonomy. This principle is based on the belief that all competent individuals have a fundamental, explicit right to decide on what they deem to be good and necessary for themselves - with specific reference to healthcare, and ultimately, continuing life. ${ }^{[4,15]}$ Worldwide, this principle has become more generally recognised and widely accepted, while the older principle of paternalism seems to be fading. In addition, this argument also seems to be strengthened when considered in terms of the SA Constitution (with reference to section 10 and 12), as mentioned above.

There are, however, certain other ethical principles that some believe stand in direct opposition to that of ultimate respect for patient autonomy. These principles are that of beneficence and nonmaleficence - in other words, acting in the best interests of patients, and not causing any harm. ${ }^{[15]}$ Therefore, the following questions are posed: would legalising PAS really be in the best interests of the individual, or would the interests of the greater community outweigh them? And would the prohibition of PAS really act in the best interests of the individual? Landman ${ }^{[4]}$ argues that PAS 'may cause no more harm 
than the withholding or withdrawal of life support' or treatment - a form of passive euthanasia that is deemed morally acceptable in SA.

A second common principle used to argue in support of PAS is that of the prevention of suffering ${ }^{[4]}$ It is widely believed that no one should have to be constrained by or live with extreme suffering - where it is believed that the only way in which the suffering can be relieved is through death. ${ }^{[4]}$ Thus being offered the legal option of PAS would ultimately be seen as allowing the patient to die with dignity. ${ }^{[15]}$ Conversely, a widely held counterargument to this so-termed 'mercy killing' is one that suggests that the perception of pain is completely subjective, and that individuals with a pessimistic outlook on life (especially regarding the prognosis of their condition) would be more susceptible to wrongfully opting for these life-ending interventions.

One, very relevant, argument made against the legalisation of PAS is that of the 'slippery slope'. This argument attempts to point to the possible undesired consequences that an action such as legalising PAS may have - thereby emphasising the point that these consequences may, in themselves, be morally worse than the actual anticipated consequences of prohibiting the action. ${ }^{[16]}$ The single most widely used argument under this category states that by legalising (active) euthanasia or PAS, one is at direct risk of pushing the society concerned down a slope that would ultimately lead it to resemble Nazi Germany. ${ }^{[17]}$ The Nazi-Germany analogy aims to accentuate the point that those who practise euthanasia and/or PAS may (inadvertently) become 'dehumanised', resulting in nonbeneficent killing. However, one author, Burgess, ${ }^{[16]}$ has attempted to counter this argument with a premise relating to soldiers:

'We know that combat soldiers are trained killers and that part of the training consists in deliberate and systematic dehumanisation. We also know that although some ex-soldiers actually do degenerate in just the way imagined - they become psychopathic killers - this is a relatively unusual outcome. [However,] even those who are trained to kill are usually fairly discriminating about whom they kill and why: if this were not the case, soldiers would be just as likely to kill their colleagues as the enemy. But if trained killers can, to a remarkable extent, be highly selective about suitable targets, why should medical practitioners slide down a slope that soldiers can (usually) resist?

It is further believed that the 'Nazi slippery slope' argument can be avoided by having additional safeguards and/or regulations that would require precautions to be enforced by law, as is the case in many countries where these practices have already been legalised. ${ }^{[16,18]}$

\section{Discussion}

Given the above descriptions, it is now possible to assess the feasibility of legalising PAS in SA. It would be appropriate, at this stage, to briefly consider SA's turbulent history - which is not too dissimilar to that of Nazi Germany. This makes the idea of the abovementioned slippery slope argument (i.e. a recurrence of possible mass genocide, via the legalisation of PAS) a somewhat stomach-turning thought, as it is believed that some level of radicalism still persists in SA. But the presence of extensive radicalism (in $\mathrm{SA}$ ) is probably a misperception, as empirical data are still lacking to prove its existence. However, the evidence presented above that patients who suffer from HIV/AIDS are more likely to be discriminated against (i.e. stigmatised and/or victimised), resulting in them subsequently opting for $\mathrm{PAS}^{\left[{ }^{[6]}\right.}$ does raise some concerns, especially given the fact that $\mathrm{SA}$ is among the countries with the highest incidence and prevalence rates of HIV/ AIDS in the world, with a reported $12.6 \%$ (confidence interval 11.7 13.5) of the population infected. ${ }^{[19]}$ Although the authors of the article attribute the heightened risk for HIV/AIDS patients to the inadequate medical treatment available at the time of the study period, this risk still needs to be considered in SA. Even though medical treatment for HIV has drastically improved over the years, treatment compliance is still a problem in the SA setting. ${ }^{[19]}$

Furthermore, SA, like the majority of the world, is slowly moving towards a culture that is more accepting of patient autonomy with regards to the patient's acceptance or refusal of medical interventions. This is evident in the teaching received in medical schools, which advocates respect of patient autonomy. However, SA still has a long way to go before it matches international standards with regards to absolute respect for patient autonomy in life-ending decisions. It is a little known fact that in SA, an advance directive, also known as a living will, is not legally binding - especially regarding end-of-life or life-ending interventions. ${ }^{[2]} \mathrm{A}$ living will may, however, serve as a proxy in determining crucial further medical management of patients who possess one. It is therefore essential, in an SA setting, to first establish the exact role and authority such advance directives have with respect to life-ending interventions. This can only be done once well-formed laws regarding these interventions have been thoroughly thought through and established.

\section{Conclusion}

The international data suggest that no increase in the number of deaths as a result of legalising PAS is to be expected, and that with the necessary safeguards and regulations in place, PAS may be performed safely. The decision to legalise it, however, is not for one person to make, as many other determinants should be considered, such as doctors' (including future doctors') willingness to perform these procedures, as well as the general public's opinion regarding these practices. What would the implications be if PAS were to be legalised, but doctors were unwilling to participate in life-ending interventions, or were completely opposed to the legalisation of PAS? Secondly, how would the public react to having these practices made legal? One can therefore only speculate as to what implications legalising PAS without fully considering or exploring all the relevant factors could have in a country where political tensions are seemingly high.

Acknowledgements. None.

Author contributions. Sole author.

Funding. None.

Conflicts of interest. None

1. Materstvedt LJ, Clark D, Ellershaw J, et al. Euthanasia and physician-assisted suicide: A view from an EAPC Ethics Task Force. Palliat Med 2003;17(2):97-101. https://doi.org/10.1191/0269216303pm673oa

2. Moodley K. End-of-life options. In: Moodley K, editor. Medical Ethics: Law and Human Rights. A South African perspective. 1st edition. Pretoria: Van Schaik, 2011:267-280.

3. Bongaarts J. How long will we live? Popul Dev Rev 2006;32(4):605-628. https:// doi.org/10.1111/j.1728-4457.2006.00144.x

4. Landman WA. The ethics of physician-assisted suicide and euthanasia. S Afr Med J 1997;87(7):866-869.

5. Chambaere K, Bilsen J, Cohen J, Onwuteaka-Philipsen BD, Mortier F, Deliens L. Physician-assisted deaths under the euthanasia law in Belgium: A populationbased survey. Can Med Ass J 2010;182(9):895-901. https://doi.org/10.1503/ cmaj.091876 
6. Battin MP, van der Heide A, Ganzini L, van der Wal G, Onwuteaka-Philipsen BD. Legal physician-assisted dying in Oregon and the Netherlands: Evidence concerning the impact on patients in 'vulnerable' groups. J Med Ethics 2007;33(10):591-597.

7. Posner RA. Aging and Old Age. Chicago: University of Chicago Press, 1997.

8. Jones DA, Paton D. How does legalisation of physician-assisted suicide affect rates of suicide? South Med J 2015;108(10):599-604. https://doi.org/10.14423/ SMJ.0000000000000349

9. Stransham-Ford $v$ the Minister of Justice and Correctional Services and Others 30 April 2015 (27401/15) (NGHC)

10. South Africa. Constitution of the Republic of South Africa, 1996

11. Minister of Justice and Correctional Services v Estate Stransham-Ford 6 December 2016 (531/2015) 2016 ZASCA 197.

12. Clarke v Hurst NO and Others 1992 (4) SA 630 (D).

13. S v Makwanyane 1995 (3) SA 391 (CC).
14. Emanuel EJ. Euthanasia and physician-assisted suicide: A review of the empirical data from the United States. Arch Intern Med 2002;162(2):142-152. https://doi. org/10.1001/archinte.162.2.142

15. Egan A. Should the state support the 'right to die'? S Afr J Bioethics Law 2008;1(2):47-52.

16. Burgess JA. The great slippery-slope argument. J Med Ethics 1993;19(3):169-174.

17. Lamb D. The slippery slope argument. In: Lamb D, ed. Down the Slippery Slope: Arguing in Applied Ethics. London: Croom Helm, 1988.

18. Schafer A. Physician-assisted suicide: The great Canadian euthanasia debate. Int J Law Psychiatr 2013;36(5-6):522-531. https://doi.org/10.1016/j.ijlp.2013.06.002

19. Shisana O, Rehle T, Simbayi LC, et al. South African National HIV Prevalence, Incidence and Behaviour Survey. Cape Town: HSRC Press, 2012.

Accepted 17 May 2018 